\title{
Pulsed Power Application of TDI-Type Pseudospark Switches
}

\author{
V.D. Bochkov, D.V. Bochkov, I.N. Gnedin and P.V. Panov \\ Pulsed Technologies Ltd., Yablochkova 5, Ryazan, Russia
}

\begin{abstract}
The module of pulsed power electrohydraulic installation equipped with a technological tank having 2 working electrodes, storing energy up to $3 \mathrm{~kJ}$ at average power of $10 \mathrm{~kW}$ was constructed and tested. As power switching elements pseudospark switches of TDI-type were used. During the tests organic materials (flax straw) were processed. In the paper various factors, affecting PSS electrodes erosion, are considered. Valuable recommendations on providing the best service time of the switches are summarized. The major object of the investigations is the development of technological system capable of providing a continuous production process with power consumption up to hundreds of $\mathrm{kWh}$ with large volumes (up to several tons) processed materials transportation. The process continuity substantially reduces cost of processing, simplifies design, and improves operational characteristics of the device and finally increases competitiveness of the production.
\end{abstract}

PACS numbers: 52.35.Bj, 52.35.Lv, 52.75.Kq, 52.77.-j, 47.35.-i

\section{Introduction}

Development of industrial applications of pulsed power technology is associated with availability of power, fast, reliable, durable and affordable switching elements. Pulsed Technologies Company has been working on construction of the switches for over 20 years [1]. More than 35 models of power switching devices of a novel generation TDI- and TPI-types have been designed and built [2]. The switches are being used in various installations all over the world [3-6].

In the report the results of experiments with TDI-thyratrons being conducted within last 2 years in pulsed power electrohydraulic systems for blast materials processing are presented. The direction emerged in 1950s and is connected with idea to process various materials by using electric discharge in a bath filled with liquid. Recently the direction has emerged again due to increase in energy resources costs, reinforcement of environmental control. The electrohydraulic processing of fibre materials (flax straw) lies in the straw refinement from lignin and obtaining fine fibres similar to cotton fibres, suitable for application in textile industry.

The pilot $10 \mathrm{~kW}$ installation operating with two electrodes, placed into a water-filled volume, was built and tested.

The frameworks of the present report allow one covering just a limited set of results of investigations.

\section{Experimental approach and apparatus}

When constructing the installation the special attention was drawn to reduction of the whole installation cost as well as to the increase in the installation components service time. A pilot $10 \mathrm{~kW}$ installation operating with two electrodes, placed into a water-filled volume, was built and tested.
Production process exploration with purpose to make a multi-electrode system was conducted by:

- Exploring of processed materials movement at the expense of discharge and hydroflow energy (electro-hydrodynamic effects).

- Design of prototypes, construction of technological volume and unloading installation, test of electrodes systems.

- Development of electrical circuits, improvement of thyratrons service time, reduction of switched charge.

- Production of thyratron drivers with low-voltage and high-voltage units, providing operation of thyratrons with cathodes under "jumping" voltage up to $30 \mathrm{kV}$ in respect of a frame of the technological tank (ground).

The frameworks of the present report allow us covering just a set of results of investigations.

\subsection{TDI-thyratrons erosion and service time}

The data of life tests for the most powerful thyratrons TDI1-150k/25 and TDI1-50k/45 allow us making the following recommendations on improvement of the thyratrons operation reliability.

The basic modes of discharge and external factors affecting the thyratrons service time include the following major ones:

A - damped discharge (aperiodic current);

$\mathrm{B}$ - ringing discharge (oscillatory current);

$\mathrm{C}$ - operation above maximum permitted current.

Besides, extremely important is the influence of thyratrons switching circuit on the service time, when the fourth factor D - Lorentz force must be considered. 


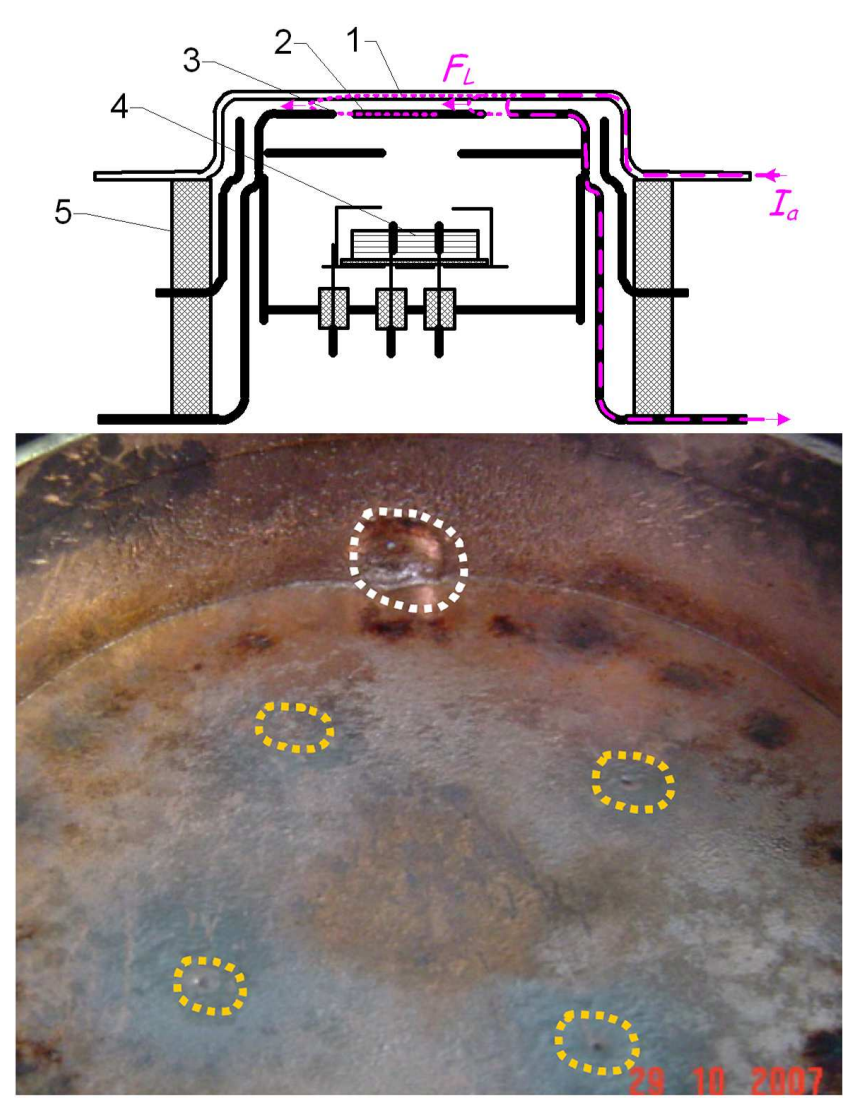

Fig. 1. TDI1-150k/25 thyratron circuit diagram and arc discharge channel traffic diagram (top). Photo of anode internal surface erosion (bottom). 1 - anode, 2 - cathode, 3 - injection hole, 4 - trigger unit; 5 - insulator. $I_{\mathrm{a}}$ - thyratron current direction in case of one-side switching; $F_{\mathrm{L}}$ - Lorentz force direction.

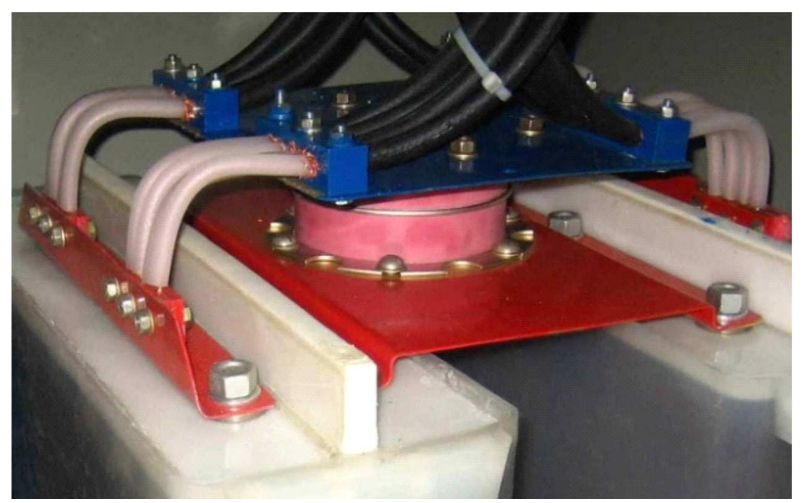

Fig. 2. Symmetrical connection of thyratron to storage and load (photo is submitted by Dr. V. Glouschenkov, SGAU, Samara, Russia).

Mode $\mathrm{A}$ is the most optimal one, when triggering starts nearby a cathode injection hole and at currents below $150 \mathrm{kA}$ the arc slightly moves from the initial position. The erosion leads to cone-shaped cathode excavation at injection holes $[1,7]$.
Current oscillations in B mode affects erosion on a greater extent than in A-mode due to the fact that in the subsequent half-waves the discharge fires and arc cathode spot appears in places with the least discharge initiation potential. The places are connected with the boundaries of heterogeneous materials or with contamination of electrodes (dielectric or semiconductor sputtering - ceramics, oxides etc.), located on the circumferences nearby dielectric walls.

Such an affixment of discharge leads to progressive materials sputtering, both electrodes and ceramics, and fast thyratron failure (reduction of hold-off voltage). In order to suppress the undesirable processes in B-mode the application of thyratrons with hollow anode (e.g. TDI1$150 \mathrm{k} / 25 \mathrm{H})$ is recommended. This construction provides affixment of discharge channels of the subsequent current half-waves nearby injection holes, thus substantially improving service life of the switch.

In C-case in the given design at currents over $150 \mathrm{kA}$ even in discharge without oscillations the arcs fired nearby the 4 injection holes. During discharge arcs are connected into the common channel thus stimulating abrupt reduction of service time due to destruction of electrodes in the central part. For this mode the modified thyratron TDI1-200k/25 delivering currents up to $200 \mathrm{kA}$ must be used.

The aforesaid is fair provided the symmetry of current feed-through is observed. When current drainage appears (over $10 \mathrm{kA}$ ), with privilege for one direction, a stronger electrodes erosion at the peripheral occurs due to discharge channels surge in this area under the influence of the Lorentz force (Fig. 1).

Figure 1 (photo) shows the erosion of internal parts of thyratron anode, caused by arc surge onto a lateral of the electrodes (pit and small hole, dotted bigger circle) and the initial erosion (four small pits, four dotted smaller circles) occurred in normal mode uniformly and coaxially to the four cathode injection holes. Basing on these data in order to compensate $F_{\mathrm{L}}$ and stabilize arc position it is recommended to balance the currents, placing external conductors - input leads at least from 2-4 adverse sides, e.g. as shown in Fig. 2.

\subsection{Pulse hydrodynamic system design and tests}

The purpose of the investigations was to design and build a technological device, capable of providing a continuous production process with power consumption up to hundreds of $\mathrm{kWh}$ without transportation of large volumes of processed materials (from hundreds kilograms up to several tons per hour).

The usual configuration being used for electrohydraulic process (Fig. 3), at the same output sharply increases quantity of tanks, materials handling equipment, cost of the installation and the whole process.

Under these conditions the best technological design of the tank comprises a tube (Fig. 4), located on elastic base with electrodes homogeneously distributed by the 

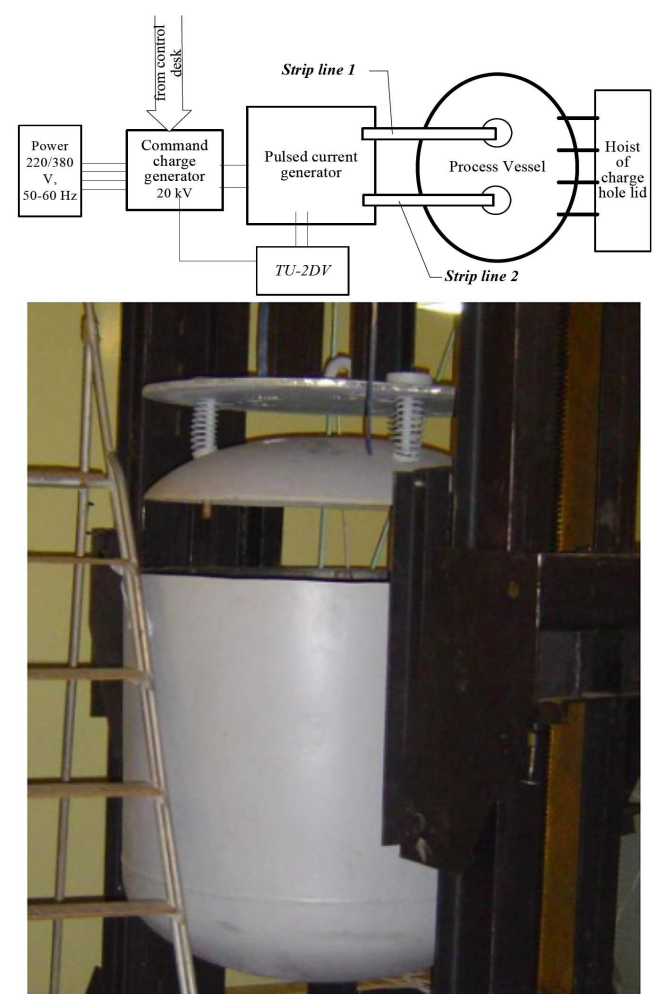

Fig. 3. Diagram of power electric part of double-electrode module of pulse electrohydraulic complex and photo of two-electrodes "vessel" variant of technological tank. TU-2DV - thyratron driver.

length of the tube. Such a tank with the electrode system provides advance of the material towards unloading point from a loading hatch at the expense of blast wave action and following liquid movement - hydroflow. The configuration allows us to exclude mechanical materials handling equipment thus increasing reliability and fail-safety of the installation within service time.

The analysis of processed flax straw allows to infer that for pulse energy about $2-3 \mathrm{~kJ}$ per electrode and frequency of $2 \mathrm{~Hz}$ an optimal time of material exposition in the discharge zone is approximately 8-12 $\mathrm{min}$. The most effective transportation and good mixing of materials with high homogeneity of processing can be achieved in the mode when the pulses are applied one by one to different electrodes (alternate feeding).

The further work was aimed to construction of a multi-electrode "tube" variant of the technological tank [8], shown in Fig. 5.

In the variant, shown in Fig. 5, the electrodes for better mixing and more homogeneous material processing are located the way to provide along with a translation of material towards unloading chamber a simultaneous circular motion. Depending on state of processing the program provides usage of either all of the electrodes or separate groups of electrodes by slowing down or acceleration of transportation. At that by the all length of circular pipe a constant mixing of the material occurs,
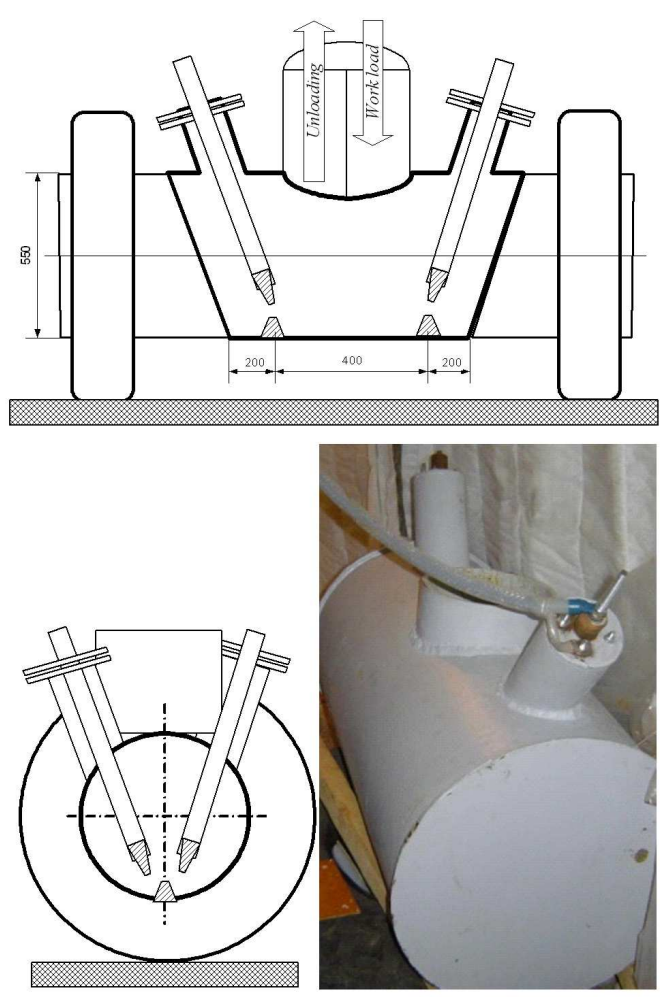

Fig. 4. Drawing and photo of two-electrodes "tube" variant of technological tank.

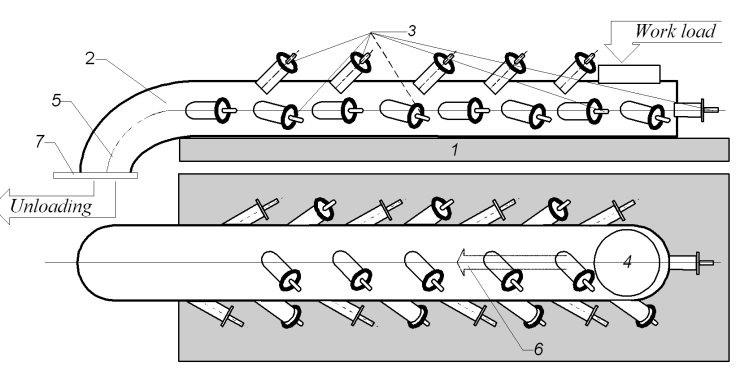

Fig. 5. Drawing of multi-electrode "tube" (circular pipe) variant of the technological tank. 1 - elastic basement, 2 - tube, 3 - electrodes, 4 - workload, 5 - unloading part, 6 - direction of flow, 7 - shutter.

thus improving homogeneity of the mass and avoiding the presence of unprocessed volumes of material.

\section{Conclusions}

TDI-thyratrons are capable of operating with sufficient reliability in diverse technological systems with total charge transfer rating of over some millions coulombs.

The thyratrons compete successfully with other state-of-the-art switches thanks to absence of constant heating, long service life, small physical dimensions and low weight, improved surge capability and low cost.

Electrical pulse hydrodynamic processing in tube technological tank offers effective transportation of materials 
and in the course of continuous processing cycle provides high quality of the material suitable for receiving fine linen. Similar construction is promising for use in processing of high volumes of various liquids, suspensions, suspended solids, e.g. mineral oil, water, concrete.

\section{Acknowledgments}

The work was supported by Pulsed Technologies Ltd Co. in the framework of the company's R\&D Programs.

\section{References}

[1] V.D. Bochkov, V.M. Dyagilev, Yu.D. Korolev, V.G. Ushich, Instrum. Exp. Techn. 41, 676 (1998).

[2] V.D. Bochkov, V.M. Djagilev, V.G. Ushich, O.B. Frants, Yu.D. Korolev, I.A. Shemyakin, K. Frank, IEEE Trans. Plasma Sci. 29, 802 (2001).

[3] O.V. Anchugov, Yu.G. Matveev, D.A. Shvedov, V.D. Bochkov, D.V. Bochkov, V.M. Dyagilev, V.G. Ushich, S.F. Mikhailov, V.G. Popov, in: Proc. 2007 PPPC, Albuquerque (NM) USA, 2007, p. 1335.
[4] A.V. Akimov, P.V. Logachev, V.D. Bochkov, D.V. Bochkov, et al., in: Proc. 2007 PPPC, Albuquerque (NM) USA, 2007, p. 1339.

[5] V.D. Bochkov, V.M. Dyagilev, V.G. Ushich, V.A. Glouschenkov, R.Yu. Yusupov et al., in: Proc. 2002 International Power Modulator Conference, Hollywood USA 2002, p. 475.

[6] V.A. Gribkov, M. Scholz, V.D. Bochkov, A.V. Dubrovsky, R. Miklaszewski, L. Karpinski, S. Lee, P. Lee, J. Phys. D, Appl. Phys. 37, 2107 (2004).

[7] V.D. Bochkov, Yu.D. Korolev, in: Encyclopedia of Low Temperature Plasma, Ed. V.E. Fortov, Nauka Publ., Moscow 2000, p. 446 (in Russian).

[8] V.D. Bochkov, Patent RF No. 2347619, priority 06.06.2007. Bulletin of Invention No. 6, 27.02.2009. 